\title{
Public health benefits and risks of fish consumption: current scientific evidence $v$. media coverage
}

\author{
Federico A Pasquarée $1, *$, Roberta Bettinetti ${ }^{1}$, Sonia Fumagalli ${ }^{1}$ and Davide A Vignati ${ }^{2,3}$ \\ 'Department of Theoretical and Applied Sciences, Insubria University, Via Mazzini 5, 21100 Varese, Italy: \\ ${ }^{2}$ CNR-IRSA, UOS Brugherio, Brugherio, Italy: ${ }^{3}$ Université de Lorraine, LIEBE, UMR 7146, Metz, France
}

Submitted 21 January 2012: Final revision received 5 June 2012: Accepted 7 August 2012: First published online 25 September 2012

\begin{abstract}
Objective: To evaluate if and how the current degree of scientific uncertainty about the safety of fish consumption is incorporated at the media level.

Design: We used a dedicated software (TalTac ${ }^{\circledR}$ ) to investigate the content of 169 news articles related to 'mercury and fish consumption' that appeared from 1990 to 2010 in the two Italian broadsheets with the highest circulation figures, in order to identify journalistic frames used in the coverage of benefits $v$. risks associated with fish consumption. Hypotheses were made on how the public might change fish consumption patterns as a result of media coverage.

Setting: Italy.

Results: The two newspapers have different agendas in covering the issue. La Repubblica appears to support the view that, besides health benefits, there may be risks associated with fish consumption, while Corriere della Sera emphasizes health benefits more than possible risks. Depending on the preferred information source, the public could: (i) reduce its fish intake; (ii) increase its fish intake; or (iii) become confused about the problem and sceptical towards the media, as a result of conflicting journalistic frames.

Conclusions: The Italian media, in cooperation with scientists, public health nutritionists and dietitians, should place more emphasis on the existence of a few fish species with high to very high $\mathrm{Hg}$ levels and relatively low contents of beneficial $n$ - 3 fatty acids (e.g. swordfish and shark). This would enable consumers to make more educated purchasing decisions to maximize the benefits of $n-3$ intake while reducing possible risks from consuming Hg-contaminated fish.
\end{abstract}

There is uncertainty among consumers regarding the health effects of fish consumption ${ }^{(1,2)}$. This situation partly reflects contrasting scientific results. Substantial evidence suggests that the incorporation of fish in the diet reduces mortality from $\mathrm{CHD}^{(3,4)}$, the leading cause of death in developed and several developing nations. However, concern exists about potential health problems from increased exposure to $\mathrm{Hg}$ via contaminated fish ${ }^{(5-9)}$. Although information about benefits and risks is crucial for consumers to make informed purchasing decisions, few studies have investigated how the knowledge of safety risks and health benefits affects consumers' food choice $^{(10,11)}$.

With regard to fish consumption, few studies have investigated consumers' perception of health benefits and risks ${ }^{(1,12)}$. One study ${ }^{(12)}$ examined the perceptions of people fishing in three coastal regions of the New York Bight to assess their knowledge of the risks and benefits of fish consumption. The outcomes clearly showed that the fishing public acknowledges the existence of risks and benefits connected with fish consumption, but has very poor knowledge of the specific risks and benefits. Furthermore, people are not sufficiently aware of the information necessary to make informed purchasing decisions, i.e. what are the possible contaminants, which fish are subject to the highest contamination levels and which sectors of the population are most at risk. Another recent paper $^{(13)}$ focused on determining hair $\mathrm{Hg}$ concentration in women of childbearing age in Taiwan and assessing risk perception in relation to fish consumption. The study found that the women involved in the research had a very poor knowledge of what kinds of fish are the safest to eat and of the potential health risks associated with contaminated fish.

Information about food health risks can have a psychological impact that depends on the trust in the information source, individual hazard perception and the specific messages conveyed by the media ${ }^{(1,14,15)}$. Although the public's perception of the fish consumption safety issue will not be determined exclusively by the views taken by a newspaper, it might indeed be affected by media information. So far, only one key study ${ }^{(2)}$ has 
attempted to determine women's perception of conflicting media messages about fish consumption and assessed the strategies that women use to make meaning of contradictory health information. In this respect, it is worth mentioning that women were among the main target publics of a 'consumer advisory' issued by the US Food and Drug Administration and the US Environmental Protection Agency in $2004^{(16)}$.

However, very little effort has been devoted to investigating if and how the current degree of scientific uncertainty on the benefits $v$. risks of fish consumption is incorporated at the media level.

\section{General framework}

$\mathrm{Hg}$, a highly reactive metal, is released into the environment by anthropogenic activities such as coal-burning, chlorine production and artisanal gold mining, and is contained in batteries, thermometers and dental amalgams ${ }^{(4)}$, although plans to eliminate $\mathrm{Hg}$ from these and other consumer products are already under implementation. Upon entering aquatic systems, either by atmospheric deposition or from watershed-based sources, $\mathrm{Hg}$ is partly converted by micro-organisms into methylmercury $(\mathrm{MeHg})^{(17)}$. $\mathrm{MeHg}$ is a contaminant of concern because of its strong tendency to bioaccumulate and biomagnify along the food chain ${ }^{(18)}$, with higher $\mathrm{MeHg}$ contents in large, long-lived predators (e.g. shark, swordfish, tilefish), intermediate levels in medium-sized predators (e.g. trout) and lowest levels in short-lived (e.g. salmon) or smaller (e.g. shrimp, clams) species $^{(3,4,9)}$.

In human adults, high exposure to $\mathrm{Hg}$ causes paresthesias, ataxia and sensory symptoms; often reversible with reduction of exposure to $\mathrm{Hg}^{(4,19,20)}$. Nowadays few people are exposed to such doses and most of the health concern for the population is related to the potential effects of chronic, low-level $\mathrm{Hg}$ exposure that could derive from fish consumption ${ }^{(4)}$. Recommendations have been issued $^{(16)}$ about consumption of a few fish species, with the aim of reducing exposure to $\mathrm{Hg}$ in pregnant women, nursing mothers and young children. Similar recommendations have not been released for the general population, since current evidence is insufficient to conclude that chronic, low-level $\mathrm{Hg}$ exposure has appreciable neurological effects beyond the interval of brain development correspondent to the first year of life ${ }^{(4)}$.

Absolute consensus has not been reached with regard to Hg-related risks for the cardiovascular system either, with specific studies highlighting adverse effects on several cardiac functions ${ }^{(21)}$ and review papers stressing that, for 1-2 servings of fatty fish per week, the benefits of regular fish consumption significantly outweigh the potential risks from $\mathrm{Hg}$ and other contaminants ${ }^{(4)}$.

Very high $\mathrm{Hg}$ levels are actually limited to a few fish species (i.e. swordfish, shark, king mackerel and tilefish) ${ }^{(9)}$ which, incidentally, are among those with low to moderate content of beneficial $n-3$ (omega-3) fatty acids ${ }^{(22)}$. A study of the nutritional $v$. toxicological conflict related to seafood consumption ${ }^{(23)}$ reports that the tolerable weekly $\mathrm{Hg}$ intake is exceeded only for Japan, Korea, Madagascar and the Philippines. However, the same study also cautions about the assumptions made to undertake a global evaluation and underlines that: (i) the intake evaluation is strongly dependent on the applied health-based guidance values (i.e. the maximum $\mathrm{Hg}$ intake per kilogram of body weight per day; a value that is not uniform across the recommendations of various regulatory or international bodies); and (ii) local contaminant concentration data are necessary for a more refined picture.

\section{Previous research on media messages about bealth issues}

Previous research ${ }^{(24)}$ has highlighted the effects of media messages about environmental hazards on the public's response, i.e. the readers of newspapers with frequent coverage of a hazard have a higher perception of the associated risks. Furthermore, media messages on hazards and related risks can lead the public to change its views and behaviours when the risks are relevant to its everyday life ${ }^{(25,26)}$.

In the last decade, there have been a few studies centred on how health-related topics are covered by the media, with regard to cancer ${ }^{(27-30)}$, human papillomavirus $^{(31,32)}$, tobacco control policies ${ }^{(33)}$, screening for cancer $^{(34)}$ and prescription drugs ${ }^{(35,36)}$. As already pointed out in the last paragraph of the introduction, very little research has focused on the public's perception of the safety of fish consumption as a result of media coverage. The only key paper published so far ${ }^{(2)}$ investigated how women make sense of conflicting media information about the risks of eating fish. Its approach focused on determining the effects of conflicting media information, rather than analysing the media message itself. Our approach can be regarded as complementary: we use a combination of qualitative and quantitative methods to analyse two major Italian newspapers with the purpose of identifying key messages and journalistic frames used in coverage of the benefits $v$. the risks of eating fish. We then attempt to suggest how the Italian public might respond to these messages and frames and how this, in turn, might influence purchasing decisions and fish consumption patterns.

\section{Methods}

\section{Newspaper selection}

We analysed the content of all news articles related to 'mercury and fish consumption' that appeared in the two broadsheets: La Repubblica and Corriere della Sera. Their online editions, Repubblica.it and Corriere.it, were also used for the analysis. They were chosen because they are 
the most widely circulated newspapers in Italy ${ }^{(37)}$. We chose to limit our analysis to the two most-read newspapers in Italy, although we acknowledge they may not be representative of the whole Italian readership. The articles were published from 1990 to 2010, spanning a 20-year period.

\section{Search strategy}

Story headlines and main body were analysed for any of the following combinations of words: 'tuna-mercury', 'swordfish-mercury', 'tuna-omega-3', 'swordfish-omega-3', 'fish-mercury', 'fish-risks', 'fish-benefits', 'fish-pollution' and 'fish-omega-3'. We did not include 'mercury' as a standalone word, as this would have yielded too many hits to stories where 'mercury' was covered without relation to the safety of fish consumption. The search yielded 169 articles that fit these criteria and represented the sample for our study.

\section{Data analysis}

The 169 news stories were analysed first qualitatively and then quantitatively to assess the presence of 'perspectives' or 'frames' in the general discourse about the health implications of fish consumption.

\section{Qualitative data analysis}

News stories are often built to take one perspective or another and to define which issues have to be regarded as important ${ }^{(33)}$. These 'perspectives' or 'frames' determine what is included or excluded from stories. A frame is the result of putting an issue in perspective so that it will express a certain meaning ${ }^{(33,38-44)}$.

While no established frames are available for dealing with the topic of the present paper, the occurrence of frames in the media coverage of health-related issues has been examined by several works ${ }^{(32,33,45)}$. To come up with frames to use for our qualitative analyses, we therefore followed the procedure described by previous authors ${ }^{(33)}$ who investigated newspaper coverage of tobacco issues. The use of the approach based on the mentioned work ${ }^{(33)}$ enabled us to identify, in the whole database of our news stories, two frames, that we named 'risk frame' and 'benefit frame'. The next step was to evaluate the extent to which the identified frames occurred in our sample of articles.

Hence, our qualitative analysis was aimed at determining: (i) whether, in each story, the 'risk frame' was dominant; (ii) whether, in each story, the 'benefit frame' was dominant; or (iii) whether there was no predominance of either the 'risk frame' or the 'benefit frame'.

\section{Quantitative data analysis}

In order to quantitatively confirm the existence of the two 'opposing' frames in our sample ('risk frame' $v$. 'benefit frame') we used TalTac ${ }^{\circledR}$, a dedicated software suitable for scanning huge databases for content and investigating the language used by the media. The most powerful feature in the software is the possibility to determine how much more (or less) often any single word occurs in the study database, compared with a reference database of 270000000 words (occurrences) contained within the software. The reference database was put together by the software's developers who uploaded all the articles published during 10 years in selected Italian newspapers. The software calculates the frequency with which any given word occurs in the study database, compares it with its average frequency in the reference database, and eventually yields a numerical value (Deviation on Occurrences, DO) for each word. This value indicates how much one particular word is over- or under-represented in the study database in comparison with the reference database.

The software calculates DO as follows:

$$
\mathrm{DO}=\frac{f-f^{*}}{\sqrt{f^{*}}},
$$

where $f$ stands for the frequency with which any word occurs in the study database, and $f^{*}$ stands for the frequency with which any word occurs in the reference database. When DO $>0$ for any given word in the study database, it means that this word occurs more frequently than it normally does in the journalistic discourse. When $\mathrm{DO}<0$ for any given word in the study database, it means that this word occurs less frequently than it normally does in the journalistic discourse ${ }^{(46)}$. The calculation of DO retains its statistical significance regardless of the total number of words in any study database.

We calculated the five words that had the highest DO values in our database of news stories, separating the articles in La Repubblica from the ones in Corriere della Sera. Both print and online versions of the two publications were analysed.

The second step of our quantitative assessment was based on the selection of a few relevant pairs of keywords from our database, which may help to quantitatively assess the presence of the already identified 'benefit frame' and 'risk frame'. We selected the following pairs of keywords with opposite semantic meanings in terms of the benefit $v$. risk discourse: (i) Omega/Mercury; (ii) Benefits/Risks; (iii) Antioxidant/Carcinogenic; (iv) Healthy/ Contaminated; (v) Prevention/Damage; and (vi) Cure-all/ Poison. We then calculated DO values for the selected pair of keywords for both broadsheets, together with their online versions.

\section{Results}

The time evolution of the print media coverage of this issue showed that, after an initial decade (1990-1999) characterized by extremely sparse stories, there has been an overall increase in the coverage from 2000 to 2010, with a peak of twenty-three articles in 2003 (Fig. 1). 


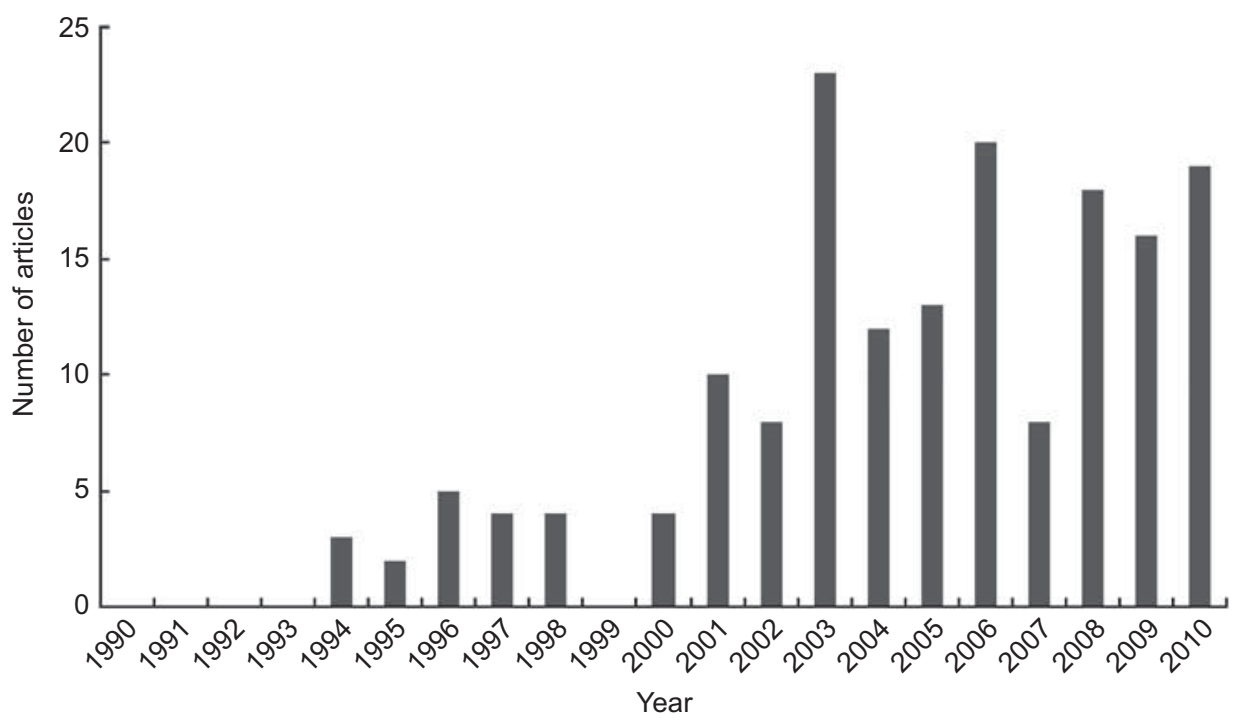

Fig. 1 Temporal trend of the number of news stories on fish consumption published from 1990 to 2010 by the Italian newspapers La Repubblica and Corriere della Sera

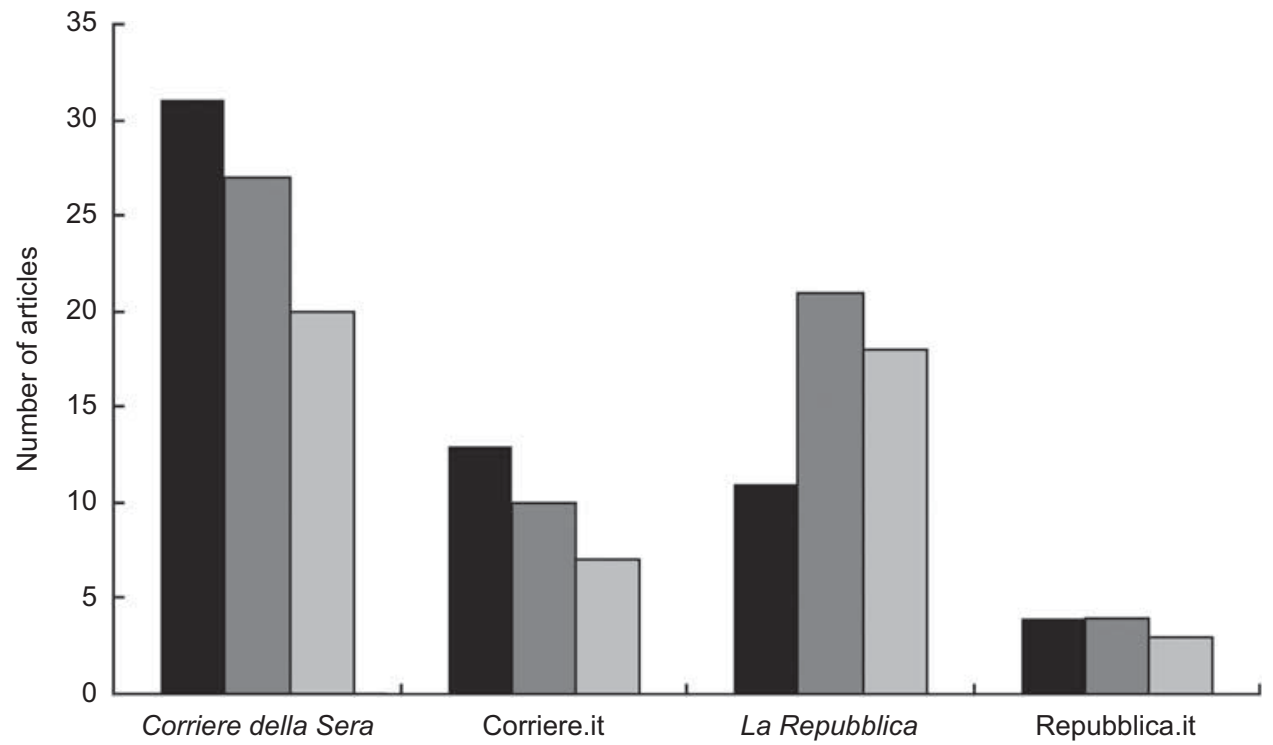

Fig. 2 Results of the qualitative analysis on the 169 news stories on fish consumption retrieved from the Italian newspapers Corriere della Sera and La Repubblica, and their respective online versions, for the period 1990-2010 ( $\square$, benefits; $\square$, risks; $\square$, balance)

This reflects the growth of media and public awareness of environment- and health-related issues in Italy over the last decade.

Our qualitative and software-based, quantitative analyses enabled us to identify and evaluate the occurrence of two frames, hereby named 'benefit frame' and 'risk frame', that characterize the overall discourse on the health implications of fish consumption. As a result of the qualitative analysis on the 169 stories, it has been possible to clearly identify the dominance of either the 'risk frame' or the 'benefit frame' in 121 of them. As shown in Fig. 2, there was an overall balance in the numbers of stories where implication of risks (sixty-two stories) and benefits (fifty-nine stories) are discussed as the main topic of the article. In the remaining forty-eight stories, a more balanced discourse on benefits and risks, more respondent to scientific evidence, emerged. The two broadsheets differed in terms of how much they represented the 'benefit frame' $v$. the 'risk frame' (Fig. 2). Considering all fifty news stories from La Repubblica, eighteen articles were 'balanced'. Out of the remaining thirty-two articles, $64 \%$ were mainly centred on risks, whereas $36 \%$ were mainly centred on benefits. In the newspaper's online version, risks and benefits were equally covered.

Considering the total of seventy-eight stories from Corriere della Sera, twenty articles were 'balanced'. Out of 
the remaining fifty-eight articles, 54\% highlighted the 'benefit frame', whereas $46 \%$ showed a dominance of the 'risk frame'. With regard to the thirty online stories from Corriere.it, seven were 'balanced'. Out of the remaining twenty-three articles, 56\% focused mainly on the benefit discourse, while $44 \%$ highlighted the risks more than the benefits.

The subsequent quantitative analysis enabled us to gain further insight into possible differences in the approach used by the two broadsheets to represent the issue. Our determination of the words with the highest DO value in the La Repubblica database resulted in the
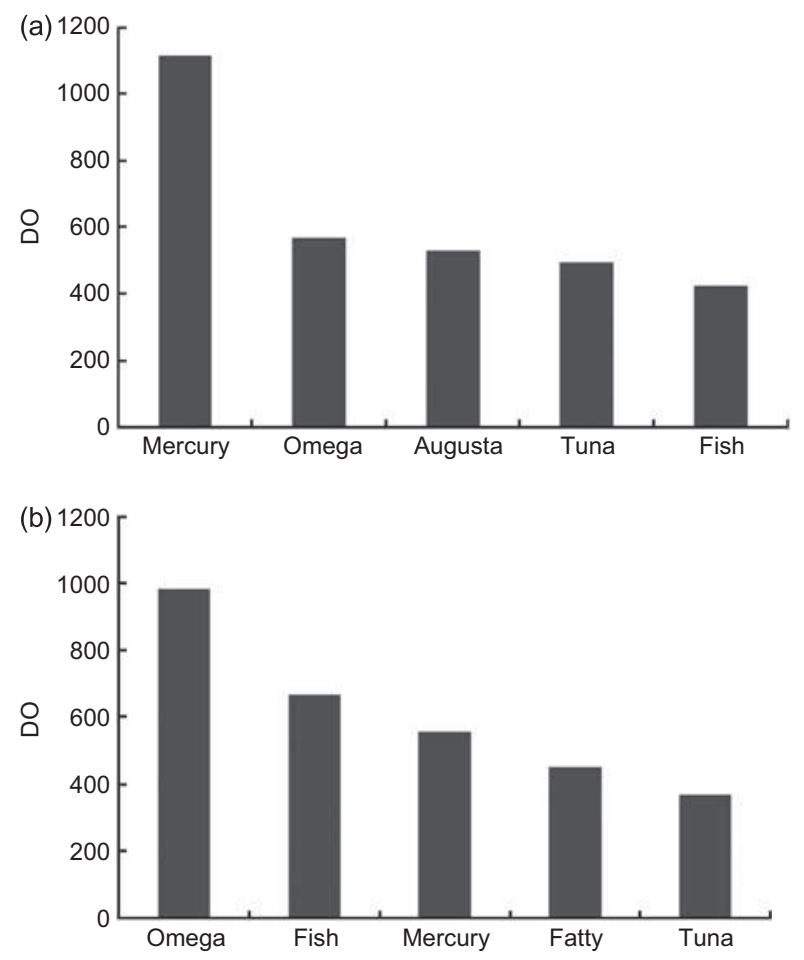

Fig. 3 The five words with the higher DO (Deviation on Occurrences) values in (a) the La Repubblica database and (b) the Corriere della Sera database following five words (Fig. 3a), in decreasing order of frequency: (i) Mercury; (ii) Omega; (iii) Augusta; (iv) Tuna; (v) Fish. The word 'Augusta' refers to the chronic environmental pollution that affects the Bay of Augusta, in Southern Italy ${ }^{(47)}$, a topic which was often covered by this newspaper. Our calculation for the Corriere della Sera database resulted (Fig. 3b) in the following words, in decreasing order of frequency: (i) Omega; (ii) Fish; (iii) Mercury; (iv) Fatty; (v) Tuna.

It is worth noting that among the three most meaningful words (DO $>1$, over-representation) in the stories from both newspapers were featured 'Omega' and 'Mercury', which can be clearly related to the correspondent benefit and risk frames. However, there is a difference in how frequently these words (and the correspondent frames) were used in the two newspapers. 'Mercury' is the most 'over-represented' word in the La Repubblica database (Fig. 3a), while the word 'Omega' has the highest DO in the Corriere della Sera database, where 'Mercury' holds the third position in the ranking (Fig. 3b). The results of our calculations of DO on pairs of opposite keywords reveal even more clearly that the two broadsheets have different approaches in covering this topic. DO values for La Repubblica clearly suggest a predominance (with no exception) in the frequency of words that can be related to the risk frame (Fig. 4a and b), whereas DO values for Corriere della Sera clearly indicate (with the exception of the Healthy/Contaminated pair) that this broadsheet tends to emphasize the benefits more than the risks associated with fish consumption (Fig. $5 \mathrm{a}$ and b).

Therefore, from our qualitative and quantitative assessment, it appears that the two studied newspapers have different agendas when addressing the health and fish consumption topic. La Repubblica has been supporting the view that, besides health benefits, there may be risks associated with fish consumption, while Corriere della Sera has been emphasizing health benefits more than possible risks.
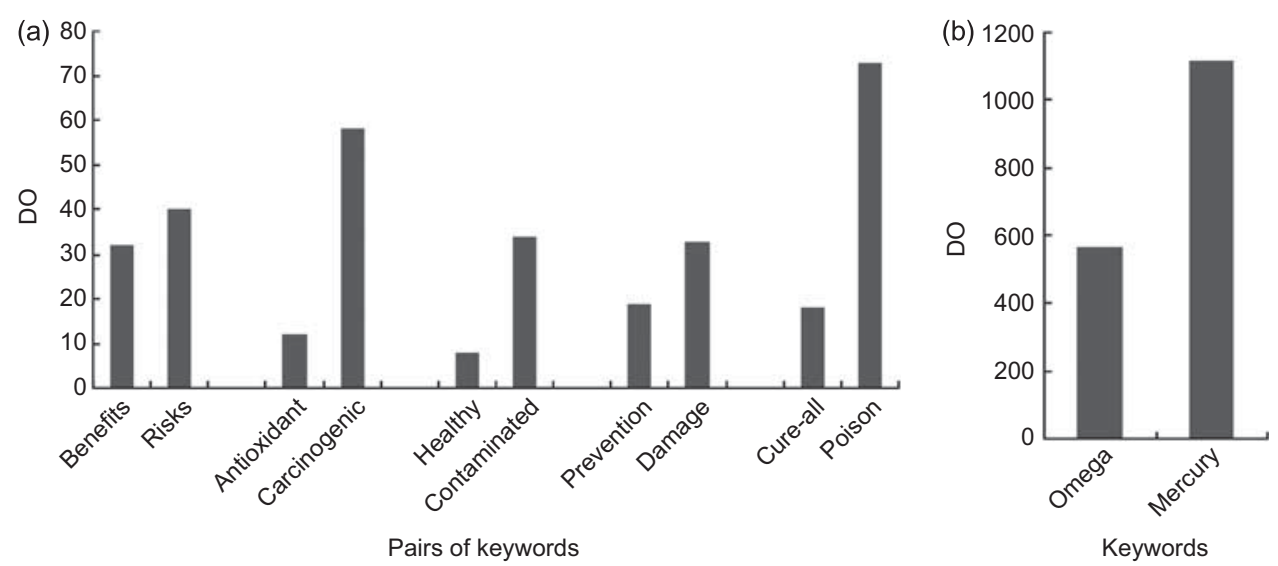

Fig. 4 La Repubblica database: (a) results of DO (Deviation on Occurrences) calculations on selected pairs of keywords; (b) results for the Omega/Mercury pair of keywords, shown separately to graphically compensate for the much higher DO values 

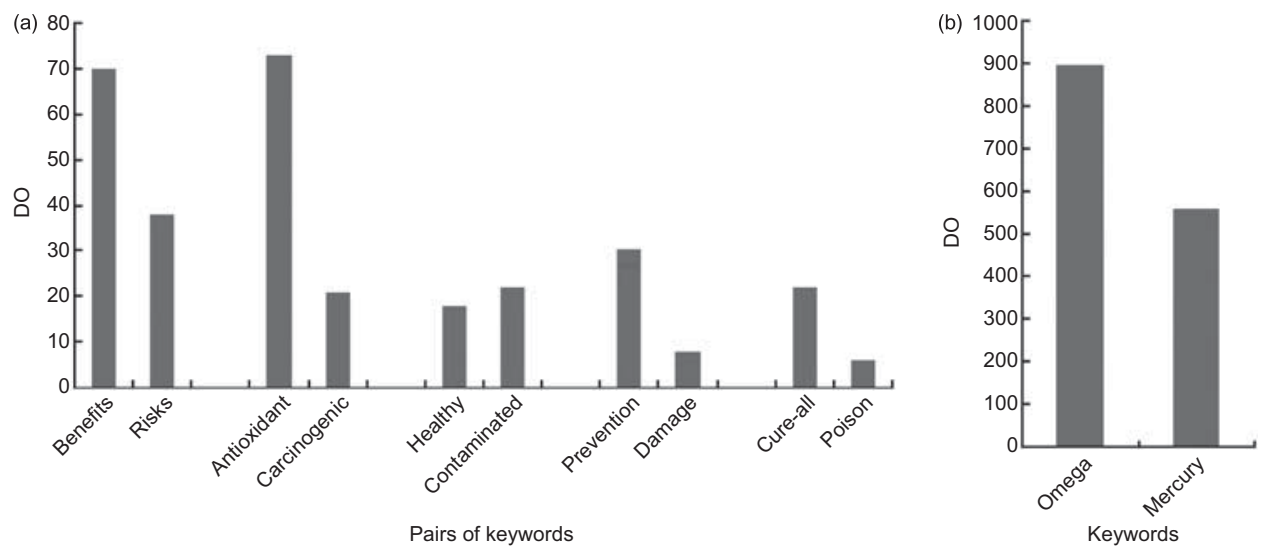

Fig. 5 Corriere della Sera database: (a) results of DO (Deviation on Occurrences) calculations on selected pairs of keywords; (b) results for the Omega/Mercury pair of keywords, shown separately to graphically compensate for the much higher DO values

\section{Discussion}

To evaluate the potential effects of the above identified frames on the Italian public's perception of this issue, we need to envision three possible scenarios that consider different audiences and a combination of them: (i) an audience that mainly/exclusively reads La Repubblica; (ii) an audience that mainly/exclusively reads Corriere della Sera; and (iii) an audience that reads both newspapers (as these broadsheets have the highest circulation in Italy, this possibility - and hence this scenario - cannot be ruled out).

1. Previous studies assessed that negative media messages about food can have a considerable impact on purchasing choices ${ }^{(48-50)}$. Moreover, it has been suggested that negative press has an impact five to seven times stronger on purchasing behaviours than favourable press ${ }^{(51,52)}$. Hence, a possible impact of the La Repubblica coverage on fish consumption patterns of its readers could be a reduction in fish intake; which, in turn, would lead to a decrease in the health benefits related to fish consumption. On the other hand, we need to consider the results of a study ${ }^{(13)}$ reporting that about $68 \%$ of Taiwanese women of childbearing age would not change their fish consumption habits even when informed that some fish contained high levels of $\mathrm{Hg}$ that may be harmful for unborn babies. However, the perception of the safety of fish consumption of the Italian public may be different from that of Asian consumers, mainly due to different cultural approaches to food. Further research is needed to shed light on this particular issue.

2. One of the possible influences of the Corriere della Sera coverage on its readership would be an increase in fish intake, in view of the potential health benefits. However, not perceiving the potential risks associated with some fish with high $\mathrm{Hg}$ levels could lead women who are or may become pregnant and nursing mothers to reduce their efforts to minimize $\mathrm{Hg}$ intake via the consumption of contaminated fish.

3. The citizens who read both newspapers will be faced with 'conflicting information', which can bring about emotional, negative consequences. Studies have shown ${ }^{(53-55)}$ that individuals can receive contradictory health information from a range of different sources. Conflicting health information can generate confusion about the correct behaviours needed to stay in good health. In addition to the above, previous research ${ }^{(2)}$, aimed at finding out how women made sense of conflicting media coverage of health implications of fish consumption, revealed that most women not only manifested confusion about the problem, but became sceptical towards health information presented in the media.

\section{Conclusions and recommendations}

Our qualitative and quantitative analysis clearly showed that the two most influential Italian newspapers (and their online versions) used different journalistic frames in their coverage of the possible presence of $\mathrm{Hg}$ in fish. While the present study has not directly assessed public perception and response to media coverage, previous research has demonstrated unequivocally that media information can have an impact on consumers' perception with respect to fish consumption ${ }^{(2)}$. As a result, consumers may face difficulties in balancing possible risks with recognized health benefits and adopting, when necessary, the appropriate behavioural changes. Hence, further research is needed about the impact of unbalanced or conflicting media messages on consumer decision making.

Moreover, the lack of specific information about risks and benefits of eating certain fish types in Italy highlights the need for a risk communication campaign that provides detailed information aimed at enabling citizens to make informed decisions. This type of communication effort has been conducted in the last decade especially in the USA and Canada ${ }^{(12,56,57)}$. 
Media alone cannot be expected to take full responsibility for such efforts and other stakeholders should engage in these communication campaigns. A recent work ${ }^{(58)}$ highlighted the role that public health nutritionists and dietitians can play in communicating how nutritional needs can be met, while at the same time enabling the protection of fish stocks. Another paper ${ }^{(59)}$ investigated how the public health nutrition workforce, in Australia, can develop policies to respond to factors that contribute to climate change. We believe that public health nutritionists and dietitians should directly commit themselves to raising consumers' awareness of the benefits and risks of fish consumption. Indeed, a tight cooperation between scientists, the public health nutrition workforce and the media would result in the elaboration of more balanced and scientifically reliable messages to the public. Such information should place more emphasis on the existence of a few fish species (i.e. swordfish, shark, king mackerel, tilefish, certain types of tuna, walleye and porgy) that have high to very high $\mathrm{Hg}$ levels ${ }^{(9)}$ and, for swordfish, shark, king mackerel and tilefish, relatively low contents of beneficial $n$-3 fatty acids ${ }^{(22)}$. This effort could help consumers to make more informed choices aimed at maximizing the benefits of $n$ - 3 intake from fish $v$. the possible risks of consuming Hg-contaminated fish.

Finally, $\mathrm{Hg}$ is only one of the contaminants that can accumulate in fish from various polluting sources ${ }^{(60)}$ and severe local pollution can reduce (and at worst eliminate) the benefits normally obtained from consuming normally safe-to-eat fish species. The creation of new journalistic messages providing consumers with all the global and local relevant information to make the safest choices in relation to fish consumption appears a necessary step to increase the societal role of the (Italian) media in making scientific information readily accessible to the public.

\section{Acknowledgements}

Sources of funding: This research received no specific grant from any funding agency in the public, commercial or not-for-profit sector. Conflicts of interest: The authors of this manuscript declare no conflict of interests. Authors' contributions: F.A.P. carried out the softwarebased analysis and wrote the manuscript; R.B. contributed to the software-based analysis and participated in writing the manuscript; S.F. carried out the qualitative analysis of the news stories and participated in writing the manuscript; D.A.V. coordinated the research and participated in writing the manuscript. Part of this research was conducted within S.F.'s final dissertation in the Program of Environmental Sciences at Insubria University. The authors are thankful to two anonymous reviewers for their helpful comments, suggestions and corrections to the original manuscript, which greatly improved the quality of the paper.

\section{References}

1. Verbeke W, Sioen I, Pieniak Z et al. (2005) Consumer perception versus scientific evidence about health benefits and safety risks from fish consumption. Public Health Nutr 8, 422-429.

2. Vardeman JE \& Aldoory L (2008) A qualitative study of how women make meaning of contradictory media messages about the risks of eating fish. Health Commun 23, 282-291.

3. Mozaffarian D \& Rimm EB (2006) Fish intake, contaminants, and human health: evaluating the risks and the benefits. JAMA 296, 1885-1899.

4. Mozaffarian D (2009) Fish, mercury, selenium and cardiovascular risk: current evidence and unanswered questions. Int $J$ Environ Res Public Health 6, 1894-1916.

5. Mahaffey KR (1999) Methylmercury: a new look at the risks. Public Health Rep 114, 396-399, 402-413.

6. Rice DC, Schoeny R \& Mahaffey K (2003) Methods and rationale for derivation of a reference dose for methylmercury by the US EPA. Risk Anal 23, 107-115.

7. Rice DC (2004) The US EPA reference dose for methylmercury: sources of uncertainty. Environ Res 95, 406-413.

8. Chan HM \& Egeland GM (2004) Fish consumption, mercury exposure, and heart diseases. Nutr Rev 62, 68-72.

9. Groth E III (2010) Ranking the contributions of commercial fish and shellfish varieties to mercury exposure in the United States: implications for risk communication. Environ Res 110, 226-236.

10. Alhakami A \& Slovic P (1994) A psychological study of the inverse relationship between perceived risk and perceived benefit. Risk Anal 14, 1085-1096.

11. Siegrist M \& Cvetkovich G (2001) Better negative than positive? Evidence of a bias for negative information about possible health dangers. Risk Anal 21, 199-206.

12. Burger J \& Gochfeld M (2009) Perceptions of the risks and benefits of fish consumption: individual choices to reduce risk and increase health benefits. Environ Res 109, 343-349.

13. Chien L-C, Gao C-S \& Lin H-H (2010) Hair mercury concentration and fish consumption: risk and perceptions of risk among women of childbearing age. Environ Res 110, 123-129.

14. Frewer LJ, Howard C, Hedderley D et al. (1997) The elaboration likelihood model and communication about food risks. Risk Anal 17, 759-770.

15. Burger J, McDermott MH, Chess C et al. (2003) Evaluating risk communication about fish consumption advisories: efficacy of a brochure versus a classroom lesson in Spanish and English. Risk Anal 23, 791-803.

16. Food and Drug Administration \& Environmental Protection Agency (2004) FDA and EPA announce the revised consumer advisory on methylmercury in fish. http://www.fda. gov/Food/FoodSafety/ProductSpecificInformation/Seafood/ FoodbornePathogensContaminants/Methylmercury/default. htm (accessed October 2011).

17. Ullrich SM, Tanton TW \& Abdrashitova SA (2001) Mercury in the aquatic environment: a review of factors affecting methylation. Crit Rev Environ Sci Technol 31, 241-293.

18. Morel FMM, Kraepiel AML \& Amyot M (1998) The chemical cycle and bioaccumulation of mercury. Annu Rev Ecol Syst 29, 543-566.

19. Gochfeld M (2003) Cases of mercury exposure, bioavailability, and absorption. Ecotoxicol Environ Saf 56, 174-179.

20. Risher JF (2004) Too much of a good thing (fish): methylmercury case study. J Environ Health 67, 9-14., 28.

21. Lim S, Chung H.-U \& Paek D (2010) Low dose mercury and hearth rate variability among community residents nearby to an industrial complex in Korea. Neurotoxicology 31, 10-16.

22. Mahaffey KR, Clickner RP \& Jeffries RA (2008) Methylmercury and omega- 3 fatty acids: co-occurrence of dietary sources with emphasis on fish and shellfish. Environ Res 107, 20-29. 
23. Sioen I, De Henauw S, Van Camp J et al. (2009) Comparison of the nutritional-toxicological conflict related to seafood consumption in different regions worldwide. Regul Toxicol Pharm 55, 219-228.

24. Wiegman O, Gutteling JM, Boer H et al. (1989) Newspaper coverage of hazards and the reactions of readers. Journalism $Q$ 66, 844-863.

25. Seydlitz R, Spencer JW \& Lundskow G (1994) Media presentations of a hazard event and the public's response: an empirical examination. Int J Mass Emer Dis 12, 279-301.

26. Spencer JW \& Triche E (1994) Media constructions of risk and safety: differential framings of hazard events. Sociol Inq 64, 199-213.

27. Brown P, Zavestoski SM, McCormick S et al. (2001) Print media coverage of environmental causation of breast cancer. Sociol Health Ill 23, 747-775.

28. Benelli E (2003) The role of the media in steering public opinion on healthcare issues. Health Policy 63, 179-186.

29. Lewison G, Tootell S, Roe P et al. (2008) How do the media report cancer research? A study of the UK's BBC website. Br J Cancer 99, 569-576.

30. Hilton S \& Hunt K (2010) Coverage of Jade Goody's cervical cancer in UK newspapers: a missed opportunity for health promotion? BMC Public Health 10, 368-374.

31. Anhang R, Stryker JE, Wright TC et al. (2003) News media coverage of human papillomavirus. Cancer 100, 308-314.

32. Hilton S, Hunt K, Langan M et al. (2010) Newsprint media representations of the introduction of the HPV vaccination programme for cervical cancer prevention in the UK (2005-2008). Soc Sci Med 70, 942-950.

33. Menashe CL \& Siegel M (1998) The power of a frame: an analysis of newspaper coverage of tobacco issues - United States, 1985-1996. J Health Commun 3, 307-325.

34. Schroy PC, Glick JT, Robinson PA et al. (2008) Has the surge in media attention increased public awareness about colorectal cancer and screening? J Commun Health 33, $1-9$.

35. Cassels A, Hughes MA, Cole C et al. (2003) Drugs in the news: an analysis of Canadian newspaper coverage on new prescription drugs. CMAJ 168, 1133-1137.

36. Mintzes B, Baver ML, Kravitz RL et al. (2003) How does direct-to-consumer advertising (DTCA) affect prescribing? A survey in primary care environments with and without legal DTCA. CMAJ 169, 405-412.

37. Accertamenti Diffusione Stampa (2011) Tiratura media quotidiani italiani (Average circulation figures of Italian Newspapers provided by the Italian Agency for the Assessment of Newspaper Circulation). http://www.adsnotizie.it/ certif/index.php (accessed May 2012).

38. Iyengar S (1991) Is Anyone Responsible? How Television Frames Political Issues. Chicago, IL: University of Chicago Press.

39. Ryan C (1991) Prime Time Activism: Media Strategies for Grassroots Organizing. Boston, MA: South End Press.

40. Entman R (1993) Framing: toward clarification of a fractured paradigm. J Commun 43, 51-58.

41. Wallack L, Dorfman L, Jernigan D et al. (1993) Media Advocacy and Public Health: Power for Prevention. Newbury Park, CA: Sage.
42. Chapman S \& Lupton D (1994) The Fight for Public Health: Principles and Practice of Media Advocacy. London: BMJ Publishing Group.

43. Schon DA \& Rein M (1994) Frame Reflection: Toward the Resolution of Intractable Policy Controversies. New York: Basic Books.

44. Wallack L \& Dorfman L (1996) Media advocacy: a strategy for advancing policy and promoting health. Health Educ $Q$ 23, 293-317.

45. Clarke JN \& Everest MM (2006) Cancer in the mass print media: fear, uncertainty and the medical model. Soc Sci Med 62, 2591-2600.

46. Bolasco S \& Pavone P (2010) Automatic dictionary- and rule-based systems for extracting information from text. Stud Class Dat Anal 5, 189-198.

47. Cundy AB, Collins PEF, Turner SD et al. (1998) 100 years of environmental change in a coastal wetland, Augusta Bay, southeast Sicily: evidence from geochemical and palaeoecological studies. Geol Soc London Spec Publ 139, 243-254.

48. Carson C \& Hassel C (1994) Educating high risk Minnesotans about dietary fats, blood cholesterol and heart diseases. I Am Diet Assoc 94, 659-660.

49. Robenstein R \& Thurman W (1996) Health risk and the demand for red meat: evidence from futures markets. Rev Agric Econ 18, 629-641.

50. de Jonge J, Frewer L, van Trijip H et al. (2004) Monitoring consumer confidence in food safety: an exploratory study. Br Food J 106, 837-849.

51. Mizerski RW (1982) An attribution explanation of the disproportionate influence of unfavorable information. J Consum Res 9, 301-310.

52. Verbeke W \& Ward RW (2001) A fresh meat almost ideal demand system incorporating negative TV press and advertising impact. Agric Econ 25, 359-374.

53. Wu L \& Hoyoung A (2010) Making sense of conflicting health information: an exploratory study. P Am Soc Inform Sci Technol 47, 1-9.

54. Eriksson-Backa K (2008) Access to health information: perceptions of barriers among elderly in a language minority. Inform Res 13, issue 4, paper 368.

55. Hembroff L \& Sierra A (1997) Sources and Perceived Reliability of Health Information. State of the State Survey, Briefing Paper no. 1998-35. East Lancing, MI: Institute for Public Policy \& Social Research, Michigan State University.

56. Jardine CG (2003) Development of a public participation and communication protocol for establishing fish consumption advisories. Risk Anal 23, 461-471.

57. Knuth B, Connelly NA, Sheehka J et al. (2003) Weighing health benefits and health risk information when consuming sport-caught fish. Risk Anal 23, 1185-1197.

58. Clonan A, Holdsworth M, Swift JA et al. (2011) The dilemma of healthy eating and environmental sustainability: the case of fish. Public Health Nutr 15, 277-284.

59. Sulda H, Coveney J \& Bentley M (2009) An investigation of the ways in which public health nutrition policy and practices can address climate change. Public Health Nutr 13, 304-313.

60. Dórea JG (2008) Persistent, bioaccumulative and toxic substances in fish: human health considerations. Sci Total Environ 400, 93-114. 